

\section{New perspectives}

The Gartner Hype Cycle, ${ }^{15}$ which helps industries and companies predict the maturity and adoption of technologies and applications, reports several new applications that need structural materials for higher operational temperatures, such as additive manufacturing and the Unmanned Aircraft System. In general, metallic systems in aerospace applications need to balance specific strength, creep resistance, and environmental stability ${ }^{16}$ The Leading Edge Aviation Propulsion (LEAP) is the first jet engine that includes three-dimensional (3D) printed fuel nozzles of a Co-Cr superalloy. ${ }^{17,18}$ On June 14, 2017, the Airbus corporation delivered the first LEAP-1A-powered A320neo aircraft to EasyJet. ${ }^{19}$ Compared to its predecessor, the A320neo saves up to $15 \%$ in fuel and reduces up to $15 \%$ $\mathrm{CO}_{2}$ emissions. ${ }^{20}$ Because of the new integrated unibody geometry of the LEAP-1A, the noise of A320neo on takeoff and landing decreased by approximately $50 \%$.

Today, a science-based systems-engineering approach is necessary to achieve such design objectives for advanced high-temperature materials. A hierarchy of computational and experimental tools needs to be integrated for the design of prototype alloys. ${ }^{21}$ As an example, in 2019, ANSYS, which develops and markets the engineering simulation software, acquired Granta Design, ${ }^{22}$ co-founded by Ashby and Cebon, a provider of the materials information technology using professional big data to develop such hierarchical computational tools to integrate materials properties into spatially resolved system simulations.

\section{Why metal mixology?}

In 2014, Gludovatz et al. reported that the CoCrFeMnNi highentropy alloy (HEA), ${ }^{24}$ which contain late transition metals such as $\mathrm{Fe}, \mathrm{Ni}, \mathrm{Co}$, and $\mathrm{Cu}$, was one of the best fractureresistant materials for cryogenic applications. ${ }^{24}$ Senkov et al. later designed refractory HEAs, which primarily consist of five or more refractory elements, and showed superior properties for high-temperature applications. ${ }^{25}$ The high-temperature strengths of several refractory HEAs and conventional stainless steel, aluminum, titanium, and nickel-based alloys are compared in Figure 1. Most of the refractory HEAs are significantly higher in strength (Table I). Senkov et al. suggest the solid solution strengthens the metallic systems. ${ }^{25}$

Continued improvements in yield strength (Figure 1) require a systematic approach to facilitate age-hardening effects for HEAs. Age hardening is the most widely used means for strengthening metal alloys. This strengthening mechanism relies more on the precipitation of desirable phases than on hardening from uniform dispersions. Strain fields introduced by the lattice mismatch between the precipitates and homogeneous matrix pin dislocations and act as a barrier to dislocation motion. ${ }^{41}$

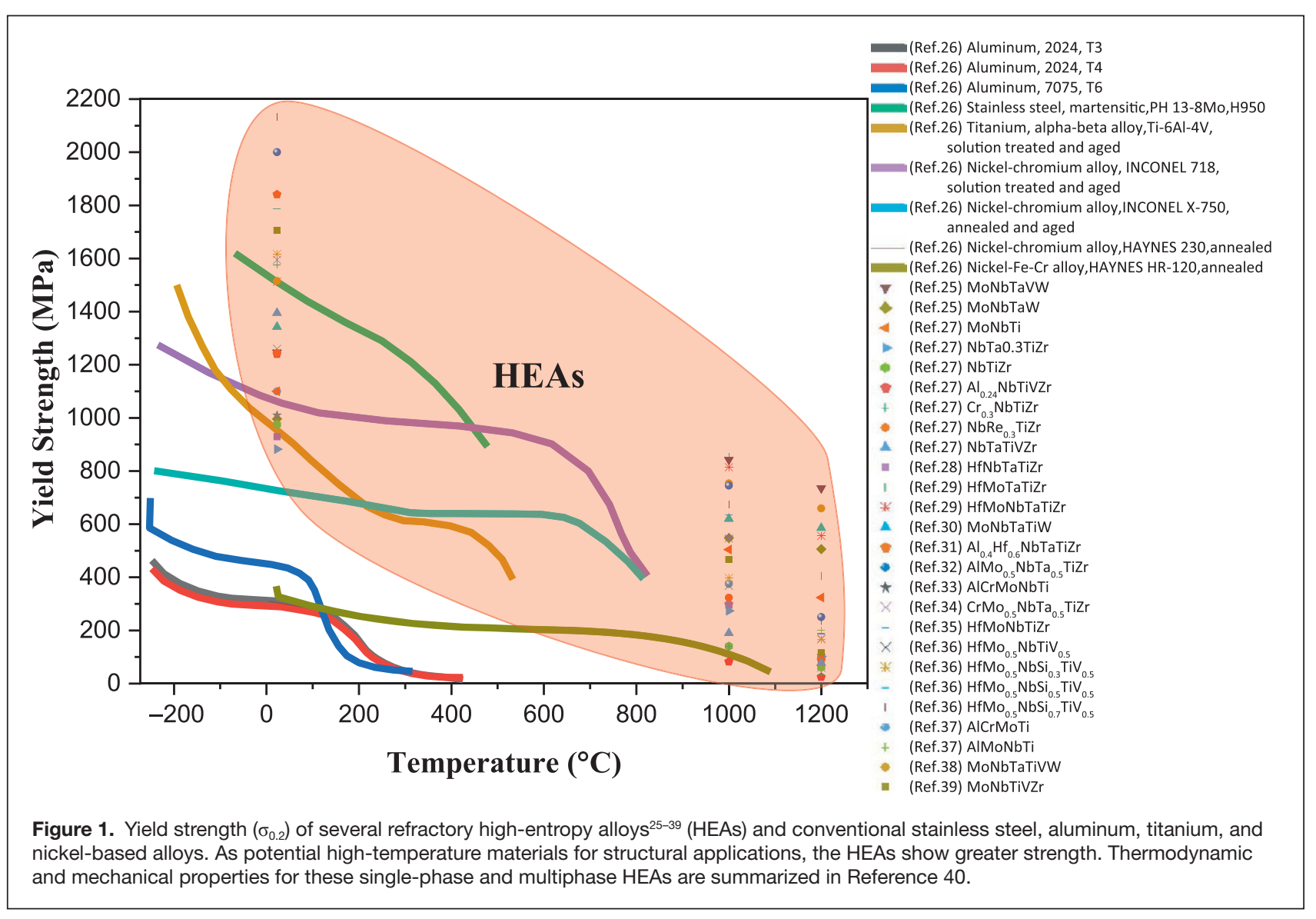


In their article in this issue, Cao et al. report ${ }^{42}$ the application of precipitation strengthening in HEAs. HEAs with multiple principal elements ${ }^{23,43}$ have shown great potential as a new class of metal mixology for high-temperature applications. ${ }^{25,44}$ In their article, Inoue et al. ${ }^{45}$ describe the latest progress in metallic alloys with elevated-temperature resistance in the form of glassy/amorphous structures, such as bulk metallic glass materials, rather than a crystalline structure. By introducing specific crystalline phases in an amorphous matrix (Figure 2), ${ }^{46}$
BMG-composite materials demonstrate improved plasticity and toughness when compared to monolithic amorphous materials. $^{47-49}$

\section{In situ high-temperature measurements using neutrons and synchrotron $x$-rays}

Spallation neutron sources have the advantage of illuminating multiple diffractions for texture-sensitive studies of materials as well as nano-precipitate diffraction. In particular, a main

\begin{tabular}{|c|c|c|c|c|}
\hline Symbols/Materials & YS at $23^{\circ} \mathrm{C}(\mathrm{MPa})$ & YS at $1000^{\circ} \mathrm{C}(\mathrm{MPa})$ & YS at $1200^{\circ} \mathrm{C}(\mathrm{MPa})$ & Ref. \\
\hline$\nabla$ MoNbTaVw & 1246 & 842 & 735 & 25 \\
\hline MoNbTaW & 996 & 548 & 506 & 25 \\
\hline$\angle_{\text {MoNbTi }}$ & 1100 & 504 & 324 & 27 \\
\hline $\mathrm{NbTa}_{0.3} \mathrm{TiZr}$ & 882 & 274 & 102 & 27 \\
\hline $\mathrm{NbTiZr}$ & 975 & 141 & 61 & 27 \\
\hline $\mathrm{Al}_{0.24} \mathrm{NbTiVZr}$ & 1240 & 82 & 24 & 27 \\
\hline$+\mathrm{Cr}_{0.3} \mathrm{NbTiZr}$ & 1576 & 139 & 32 & 27 \\
\hline $\mathrm{NbRe}_{0.3} \mathrm{TiZr}$ & 1244 & 323 & 89 & 27 \\
\hline$\Delta_{\text {NbTaTiVZr }}$ & 1395 & 190 & 78 & 27 \\
\hline HfNbTaTiZr & 929 & 295 & 92 & 28 \\
\hline I HfMoTaTiZr & 1600 & 855 & 404 & 29 \\
\hline * HfMoNbTaTiZr & 1512 & 814 & 556 & 29 \\
\hline MoNbTaTiW & 1343 & 620 & 586 & 30 \\
\hline $\mathrm{Al}_{0.4} \mathrm{Hf}_{0.6} \mathrm{NbTaTiZr}$ & 1841 & 298 & 89 & 31 \\
\hline $\mathrm{AlMo}_{0.5} \mathrm{NbTa}_{0.5} \mathrm{TiZr}$ & 2000 & 745 & 250 & 32 \\
\hline$\widehat{\wedge}$ AICrMoNbTi & 1010 & 550 & 105 & 33 \\
\hline$X_{\mathrm{CrMo}_{0.5} \mathrm{NbTa}_{0.5} \mathrm{TiZr}}$ & 1595 & 546 & 170 & 34 \\
\hline — HfMoNbTiZr & 1575 & 635 & 187 & 35 \\
\hline$X_{\mathrm{HfMO}_{0.5} \mathrm{NbTiV}_{0.5}}$ & 1260 & 368 & 60 & 36 \\
\hline * $\mathrm{HfMo}_{0.5} \mathrm{NbSi}_{0.3} \mathrm{TiV}_{0.5}$ & 1617 & 398 & 166 & 36 \\
\hline$-\mathrm{HfMo}_{0.5} \mathrm{NbSi}_{0.5} \mathrm{TiV}_{0.5}$ & 1787 & 614 & 188 & 36 \\
\hline I $\mathrm{HfMo}_{0.5} \mathrm{NbSi}_{0.7} \mathrm{TiV}_{0.5}$ & 2134 & 673 & 235 & 36 \\
\hline AlCrMoti & 1100 & 375 & 100 & 37 \\
\hline+ AlMoNbTi & 1100 & 540 & 200 & 37 \\
\hline MoNbTaTiVw & 1515 & 753 & 659 & 38 \\
\hline MoNbTiVZr & 1706 & 467 & 116 & 39 \\
\hline
\end{tabular}
advantage of the in situ neutron environment is the possibility of investigating the evolution of microstructures since identical specimens are monitored during the entire experimental time and are subjected to the changes of the control parameters. Moreover, most of the neutrondiffraction instruments are equipped with the strobing software, such as the VULCAN Data Reduction and Interactive Visualization softwarE (VDRIVE) ${ }^{50}$ of VULCAN at the Spallation Neutron Source (SNS) of Oak Ridge National Laboratory (ORNL), which can reduce the data at the end of each test and is much more useful. The strobing system is a continuously run software utilizing event-based data acquisition where each neutron carries a time stamp. In this case, diffraction data can be collected continuously and binned later according to the desired time scale. Besides studying conventional materials, advanced in situ neutron diffraction would be useful in studying HEAs. ${ }^{51-53}$

TAKUMI, ${ }^{54}$ a materials engineering diffractometer located in Japan at the Japan Proton Accelerator Research Complex, is another spallationneutron-source diffractometer that is capable of various in situ environments, including elevated-temperature measurements. TAKUMI's orientationdependent data-acquisition 


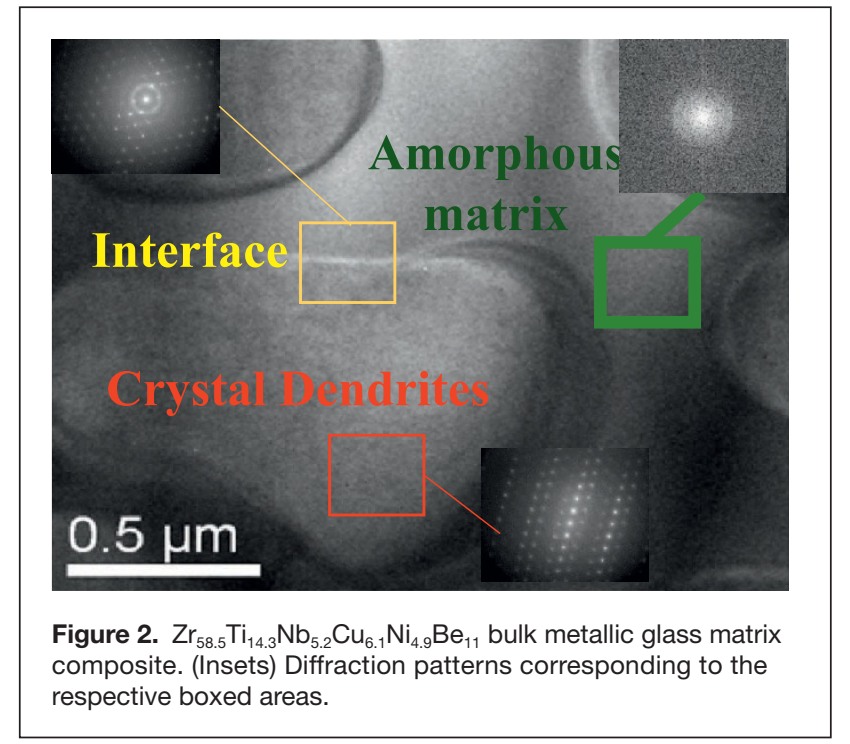

function can couple various detectors (Figure 3a). Figure 3b shows the high-temperature heating setup for TAKUMI for in situ loading. Figure $3 \mathrm{c}$ shows the spatially resolved temperature mapping for the sample and the environment; meanwhile, additional thermocouples are attached on the sample to measure the temperatures.

Besides VULCAN and TAKUMI, the Spectrometer for Materials Research at Temperature and Stress at the Los Alamos Neutron Science Center ${ }^{55}$ in the United States, and ENGIN-X ${ }^{56}$ of the ISIS at the Rutherford Appleton Laboratory in the United Kingdom are also capable of similar types of measurements. For a reactor-based neutron diffractometer, the Residual Stress Instrument (RSI) installed at the HighFlux Advanced Neutron Application Reactor (HANARO) of the Korea Atomic Energy Research Institute (KAERI), is a wide-angle neutron diffractometer optimized for strain-stress scanning and deformation behavior studies for polycrystalline metals and alloys ${ }^{57}$ (Figure 4).

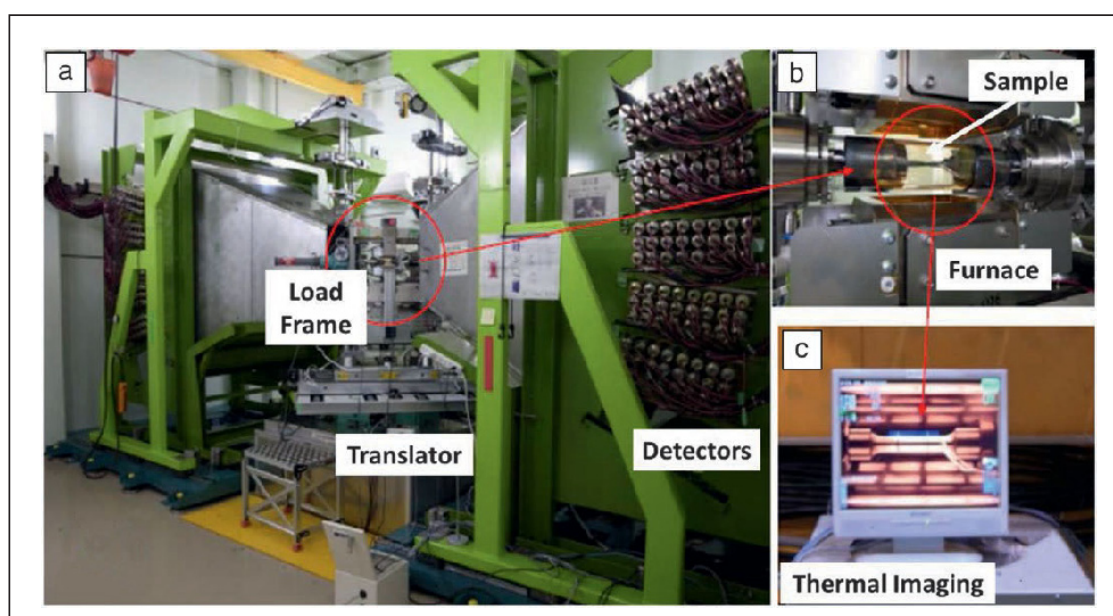

Figure 3. (a) The TAKUMI instrument (Republic of Korea); (b) load frame equipped with a high-temperature chamber; and (c) temperature-mapping monitor. ${ }^{54}$
Similarly, synchrotron x-rays can also illuminate the microstructure with high penetration. For in situ heating experiments, the Taiwan Photon Source (TPS) in Taiwan has two stations..$^{58}$ The x-ray nano-diffraction (TPS-21A) provides spatially resolved mapping for elements, phases, orientation, residual strain-stress, and dislocations at a resolution of $100 \times 100 \times 50 \mathrm{~nm} .{ }^{59}$ For hightemperature heating, temporally coherent $\mathrm{x}$-ray diffraction (TPS09A) can heat the samples up to almost $1200 \mathrm{~K} .{ }^{60} \mathrm{In}$ addition to studying conventional alloys, advanced synchrotron $\mathrm{x}$-ray diffraction can be effective in investigating HEAs. ${ }^{61,62}$

Several neutron and synchrotron $\mathrm{x}$-ray instruments have been reviewed elsewhere. ${ }^{63}$ Based on the different perspectives of heating effects, various in situ measurements can be applied. Crystallographic slip and associated dislocation activities during deformation at different temperatures can be revealed using these instruments. By refining the diffraction profiles with the general structure analysis software, peak components enable the investigation of dislocations and the average distance between patterned-dislocation structures, ${ }^{64}$ which will be useful for probing the plastic behavior of HEAs.

Besides advancements in high-temperature experimental environments, Agnew et al. and Tome et al.'s self-consistent model couples bulk properties and diffraction data, enabling crystal-plasticity-based investigations. ${ }^{65}$ A self-consistent model compares the internal strains within a polycrystalline alloy measured during deformation testing by in situ neutron diffraction. Using Tome's self-consistent simulation code, information about the operation of slip and mechanical twinning modes as a function of strain can be obtained. In their article in this issue, Wang et al. repor ${ }^{66}$ modeling twinning, detwinning, and dynamic recrystallization of magnesium alloys.

\section{In the age of artificial intelligence and machine learning}

A group from Rolls-Royce and the University of Cambridge recently reported the successful use of a neural network to design high-temperature molybdenum-based HEAs ${ }^{67}$ Their artificial intelligence (AI) tool evaluated the cost, phase stability, precipitate content, yield stress, and hardness simultaneously, and their experimental results validated that the predicted alloy fulfills the computational predictions. Tshitoyan et al. report a machine-learning algorithm that successfully identifies and predicts emerging fields within the broad materials field without guidance from humans. ${ }^{68}$ Their material informatics system integrates high-throughput experiments, computations, and data-driven methods from 3.3 million published abstracts, which enable new materials design. The AI technology thus effectively saves time when compared to traditional methods used by humans. For materials development, the Materials Genome Initiative has shown significant progress in the computational simulation and modeling of materials. ${ }^{69}$ 

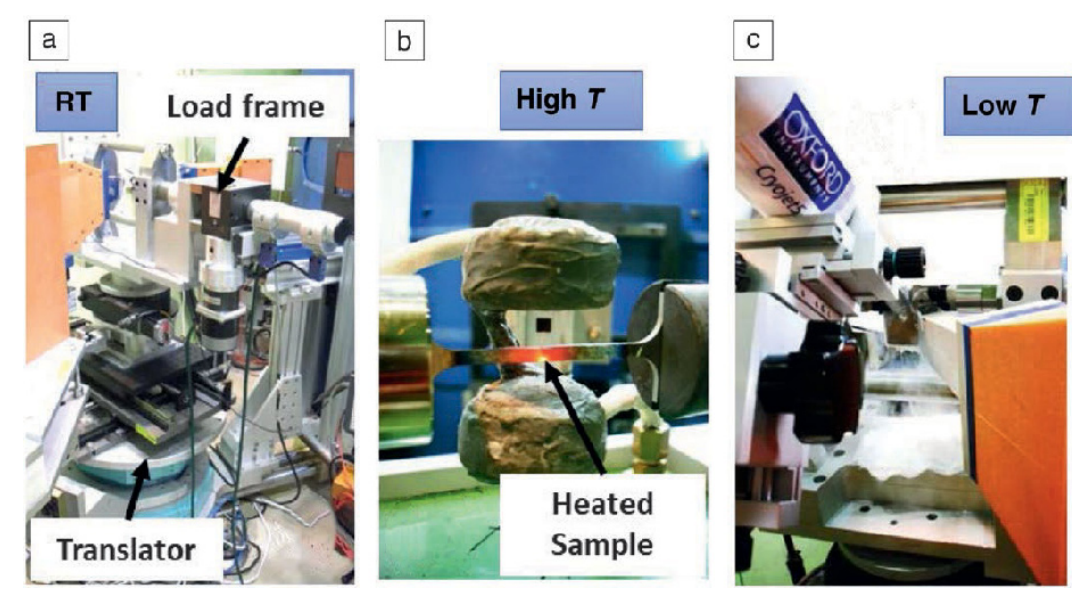

Figure 4. Three different environmental temperature setups for measuring the residual stress in the High-Flux Advanced Neutron Application Reactor (HANARO): (a) room-temperature, (b) high-temperature, and (c) low-temperature in situ measurements. Note: $T$, temperature.

also reveals unprecedented thermal stability up to $1023 \mathrm{~K}$, which is $75 \%$ of the melting temperature of $\mathrm{Cu}$. Humphry-Baker et al. established a mechanochemical reaction between solid phases for 3D printing high-specific strength metals to reduce specific strengths. ${ }^{76}$ Meanwhile, Lin et al. strengthen metals using UFG/nanocrystalline phases, unlike conventional microstructure-refinement methods. ${ }^{77}$

\section{Summary}

This issue explores the state of the latest metal mixology for high-temperature applications. The microstructural degradation and failure mechanisms of the materials subjected to heating are reported for future applications associated with complex mechanical and thermal-loading conditions during service. The objective of this issue is to review modern tools,

Although text mining does demonstrate superior capability for materials discovery, ${ }^{68}$ most data are from traditional experiments. Hence, the data domain is limited by conventional measurements, such as microstructure images. Meanwhile, the types of data collected from various instruments and with different resolutions, such as neutrons and high-energy synchrotron x-rays, are different from what is collected from traditional routine measurements. An advanced photon source can penetrate bulk materials, which can yield complementary ensemble average with a much greater sample size.

With the advances in synchrotron x-ray and neutron facilities, the neutron and synchrotron x-ray diffractometers are being equipped with load frames, a furnace, and other various sample environments. Hence, real-time in situ diffraction measurements are possible using these facilities. For example, VULCAN $^{70-72}$ is dedicated to studying the mechanical behavior of materials at the SNS of ORNL. The special feature of this diverse sample environment bridges traditional mechanical tests and the underlying microstructure characterizations. In their article in this issue, An et al. ${ }^{73}$ demonstrate several unique examples of in situ measurements, which now are routine operations of VULCAN.

Extension of the AI technology to correlate in situ advanced light-source results, traditional protocols, and high-throughput examinations is expected in future elevated-temperature materials development, including HEAs. ${ }^{74}$

\section{Further advances and opportunities}

New metallurgical routes facilitating nanotechnology to explore the new territory of high specific strength for elevated-temperature metals are expected for structural applications. Researchers fabricated bulk ultrafine-grained (UFG)/nanocrystalline metals via slow cooling by instilling a continuous nucleation and growth control mechanism during slow cooling. ${ }^{75}$ The bulk UFG/nanocrystalline metal with nanoparticles (bulk $\mathrm{Cu}$ ingots with WC nanoparticles) integrated with focused materials, to report innovative metallic systems, mainly HEAs for high-temperature applications. The issue explores advanced metallic systems of HEAs and BMGs, modern characterization, and computational tools for the development of the high-temperature metals, and creep behavior and thermal stability of some HEAs. Specifically, at higher temperatures, vacancy-induced behavior becomes critical, especially for HEAS. ${ }^{78}$ Lin et al. ${ }^{79}$ review some of the latest results of the creep for HEAS for this emergent field via nanoindentation technology. The content also includes alloy design, microstructure engineering, process development, machine-learning, high-throughput technology, and mechanistic modeling for deformation.

\section{Acknowledgments}

We thank C. Daniel of the Oak Ridge National Laboratory (ORNL) for his help with this introductory article. We sincerely appreciate C.-C. Kao, National Chiao Tung University. E.W.H. is grateful for the financial support of the Ministry of Science and Technology (Taiwan) Program Nos. 107-2628-E-009-001MY3, 107-3017-F-007-003, and 108-2221-E-009-131-MY4. The present work was financially supported by the "High Entropy Materials Center" from The Featured Areas Research Center Program within the framework of the Higher Education Sprout Project of the Ministry of Education in Taiwan. P.K.L. appreciates support from the US Army Research Office Project Nos. W911NF-13-1-0438 and W911NF-19-2-0049 with program managers, M.P. Bakas, S.N. Mathaudhu, and D.M. Stepp. P.K.L. thanks the National Science Foundation (DMR-1611180 and 1809640) with program directors, G. Shiflet and D. Farkas. E.W.H. thanks the National Synchrotron Radiation Research Center (NSRRC) Neutron Programs.

\section{References}

1. K. Lu, Science 328, 319 (2010).

2. N.S. Stoloff, C.T. Liu, S.C. Deevi, Intermetallics 8, 1313 (2000). 
3. A. Alamo, V. Lambard, X. Averty, M.H. Mathon, J. Nucl. Mater. 329, 333 (2004) 4. R. Darolia, JOM 43, 44 (1991).

5. M. Heilmaier, M. Krüger, H. Saage, J. Rösler, D. Mukherii, U. Glatzel, R. Völkl, R. Hüttner, G. Eggeler, Ch. Somsen, T. Depka, H.-J. Christ, B. Gorr, S. Burk, JOM 61, 61 (2009).

6. M.F. Ashby, A.L. Greer, Scr. Mater. 54, 321 (2006).

7. J. Jewell, V. Vinichenko, L. Nacke, A. Cherp, Nat. Clim. Change 9, 592 (2019)

8. W. Peng, F. Wagner, M.V. Ramana, H. Zhai, M.J. Small, C. Dalin, X. Zhang, D.L. Mauzerall, Nat. Sustain. 1, 693 (2018).

9. C. Oberschelp, S. Pfister, C.E. Raptis, S. Hellweg, Nat. Sustain. 2, 113 (2019) 10. S. Chu, A. Majumdar, Nature 488, 294 (2012).

11. Bright Hub Engineering, "What Is a Supercritical Power Plant?" (June 18, 2015), http://www.brighthubengineering.com/power-plants/32893-what-is-asupercritical-power-plant.

12. https://energypost.eu/how-much-do-ultra-supercritical-coal-plants-reallyreduce-air-pollution.

13. H.K.D.H. Bhadeshia, ISIJ Int. 41, 626 (2001)

14. R. Darolia, Int. Mater. Rev. 64,355 (2019).

15. J. Fenn, M. Blosch, (2019), https://www.gartner.com/en/documents/3887767. 16. P.R. Subramanian, M.G. Mendiratta, D.M. Dimiduk, JOM 48, 33 (1996).

17. https://www.cfmaeroengines.com/engines/leap.

18. https://www.ge.com/reports/post/116402870270/the-faa-cleared-the-first-3dprinted-part-to-fly-2.

19. J. Dubon, (2017), https://www.airbus.com/newsroom/press-releases/en/ 2017/06/easyjet-receives-first-of-130-a320neo-aircraft.html.

20. https://www.cfmaeroengines.com/press-articles/easyjet-takes-delivery-firstleap-1a-powered-a320neo.

21. M. Seifi, A. Salem, J. Beuth, 0. Harrysson, J.J. Lewandowski, JOM68, 747 (2016) 22. T. Smithyman, (2019), https://grantadesign.com/news_articles/ansys-andmaterial-intelligence-leader-granta-design-sign-definitive-acquisition-agreement. 23. J.-W. Yeh, S.-K. Chen, S.-J. Lin, J.-Y. Gan, T.-S. Chin, T.-T. Shun, C.-H. Tsau, S.-Y. Chang, Adv. Eng. Mater. 6, 299 (2004)

24. B. Gludovatz, A. Hohenwarter, D. Catoor, E.H. Chang, E.P. George, R.O. Ritchie, Science 345, 1153 (2014).

25. O.N. Senkov, G.B. Wilks, D.B. Miracle, C.P. Chuang, P.K. Liaw, Intermetallics 18, 1758 (2010).

26. CES Selector software, Granta Design Limited, Cambridge, UK, (2018), www.grantadesign.com.

27. O.N. Senkov, D.B. Miracle, K.J. Chaput, J.-P. Couzinie, J. Mater. Res. 33, 3092 (2018).

28. 0.N. Senkov, J.M. Scott, S.V. Senkova, D.B. Miracle, C.F. Woodward, J. Alloys Compd. 509, 6043 (2011).

29. C.-C. Juan, M.-H. Tsai, C.-W. Tsai, C.-M. Lin, W.-R. Wang, C.-C. Yang, S.-K. Chen, S.-J. Lin, J.-W. Yeh, Intermetallics 62, 76 (2015).

30. Z.D. Han, N. Chen, S.F. Zhao, L.W. Fan, G.N. Yang, Y. Shao, K.F. Yao Intermetallics 84, 153 (2017).

31. O.N. Senkov, S.V. Senkova, C. Woodward, Acta Mater. 68, 214 (2014).

32. J. Jensen, "Characterization of a High Strength, Refractory High Entropy Alloy, AlMo0.5NbTa0.5TiZr," PhD thesis, The Ohio State University, Columbus, $\mathrm{OH}$ (2017).

33. H. Chen, A. Kauffmann, B. Gorr, D. Schliephake, C. Seemüller, J.N. Wagner, H.-J. Christ, M. Heilmaier, J. Alloys Compd. 661, 206 (2016).

34. O.N. Senkov, C.F. Woodward, Mater. Sci. Eng. A 529, 311 (2011)

35. N.N. Guo, L. Wang, L.S. Luo, X.Z. Li, Y.Q. Su, J.J. Guo, H.Z. Fu, Mater. Des. 81, 87 (2015).

36. Y. Liu, Y. Zhang, H. Zhang, N. Wang, X. Chen, H. Zhang, Y. Li, J. Alloys Compd. 694, 869 (2017).

37. H. Chen, A. Kauffmann, S. Laube, I.-C. Choi, R. Schwaiger, Y. Huang K. Lichtenberg, F. Müller, B. Gorr, H.-J. Christ, M. Heilmaier, Metall. Mater. Trans. A 49, $772(2017)$

38. B. Zhang, M.C. Gao, Y. Zhang, S. Yang, S.M. Guo, Mater. Sci. Technol. 31 , 1207 (2015)

39. Y. Zhang, X. Yang, P.K. Liaw, JOM 64, 830 (2012).

40. O.N. Senkov, S. Gorsse, D.B. Miracle, Acta Mater. 175, 394 (2019).

41. E.W. Huang, P.K. Liaw, L. Porcar, Y. Liu, Y.-L. Liu, J.-J. Kai, W.-R. Chen, Appl. Phys. Lett. 93, 161904 (2008).

42. B. Cao, T. Yang, W.-J. Liu, C.T. Liu, MRS Bull. 44 (11), 854 (2019).

43. Y. Zhang, T.T. Zuo, Z. Tang, M.C. Gao, K.A. Dahmen, P.K. Liaw, Z.P. Lu, Prog. Mater. Sci. 61, 1 (2014).

44. D.B. Miracle, O.N. Senkov, Acta Mater. 122, 448 (2017).

45. A. Inoue, F.L. Kong, S.L. Zhu, A.L. Greer, MRS Bull. 44 (11), 867 (2019).

46. E.-W. Huang, J. Qiao, B. Winiarski, W.-J. Lee, M. Scheel, C.-P. Chuang, P.K. Liaw, Y.-C. Lo, Y. Zhang, M. Di Michiel, Sci. Rep. 4, 4394 (2014).

47. W.H. Wang, Prog. Mater. Sci. 52, 540 (2007)

48. J.W. Qiao, A.C. Sun, E.W. Huang, Y. Zhang, P.K. Liaw, C.P. Chuang, Acta Mater 59, 4126 (2011).

49. J. Qiao, H. Jia, P.K. Liaw, Mater. Sci. Eng. R 100, 1 (2016).
50. K. An, VDRIVE-Data Reduction and Interactive Visualization Software for Event Mode Neutron Diffraction (2012).

51. C. Lee, G. Song, M.C. Gao, R. Feng, P. Chen, J. Brechtl, Y. Chen, K. An, W. Guo, J.D. Poplawsky, S. Li, A.T. Samaei, W. Chen, A. Hu, H. Choo, P.K. Liaw, Acta Mater. 160, 158 (2018).

52. L.J. Santodonato, Y. Zhang, M. Feygenson, C.M. Parish, M.C. Gao, R.J.K. Weber, J.C. Neuefeind, Z. Tang, P.K. Liaw, Nat. Comm. 6, 5964 (2015)

53. H. Diao, D. Ma, R. Feng, T. Liu, C. Pu, C. Zhang, W. Guo, J.D. Poplawsky, Y. Gao, P.K. Liaw, Mater. Sci. Eng. A 742, 636 (2019).

54. S. Harjo, T. Ito, K. Aizawa, H. Arima, J. Abe, A. Moriai, T. Iwahashi, T. Kamiyama, Mater. Sci. Forum 681, 443 (2011)

55. M.A.M. Bourke, D.C. Dunand, E. Ustundag, Appl. Phys. A 74, s1707 (2002). 56. J.R. Santisteban, M.R. Daymond, J.A. James, L. Edwards, J. Appl. Crystallogr 39, 812 (2006).

57. W. Woo, E.-W. Huang, J.-W. Yeh, H. Choo, C. Lee, S.-Y. Tu, Intermetallics 62, 1 (2015)

58. Y.-C. Liu, C.H. Chen, J.Y. Chen, M.S. Chiu, P.J. Chou, C.S. Huang, S. Fann, C.C. Kuo, T.Y. Lee, C.C. Liang, J. Phys. Conf. Ser. 874, 012020 (2017).

59. X. Chen, C. Dejoie, T. Jiang, C.-S. Ku, N. Tamura, MRS Bull. 41, 445 (2016).

60. Y.-W. Tsai, Y.-Y. Chang, Y.-H. Wu, K.-Y. Lee, S.-L. Liu, S.-L. Chang, Opt. Express 24, 30360 (2016).

61. W. Guo, W. Dmowski, J.-Y. Noh, P. Rack, P.K. Liaw, Metall. Mater. Trans. A 44A, 1994 (2013).

62. B. Cheng, F. Zhang, H. Lou, X. Chen, P.K. Liaw, J. Yan, Z. Zeng, Y. Ding, Q. Zeng, Scr. Mater. 161, 88 (2019).

63. S. Calder, K. An, R. Boehler, C.R. Dela Cruz, M.D. Frontzek, M. Guthrie, B. Haberl, A. Huq, S.A.J. Kimber, J. Liu, J.J. Molaison, J. Neuefeind, K. Page, A.M. dos Santos, K.M. Taddei, C. Tulk, M.G. Tucker, Rev. Sci. Instrum. 89, 092701 (2018).

64. E.W. Huang, R.I. Barabash, B. Clausen, Y.-L. Liu, J.-J. Kai, G.E. Ice, K.P. Woods, P.K. Liaw, Int. J. Plast. 26, 1124 (2010).

65. S.R. Agnew, C.N. Tomé, D.W. Brown, T.M. Holden, S.C. Vogel, Scr. Mater 48, $1003(2003)$

66. H. Wang, S. Li, D. Li, G. Proust, Y. Gan, K. Yan, D. Tang, P. Wu, Y. Peng, MRS Bull. 44 (11), 873 (2019).

67. B.D. Conduit, N.G. Jones, H.J. Stone, G.J. Conduit, Scr. Mater. 146, 82 (2018) 68. V. Tshitoyan, J. Dagdelen, L. Weston, A. Dunn, Z. Rong, O. Kononova, K.A. Persson, G. Ceder, A. Jain, Nature 571, 95 (2019)

69. M.L. Green, C.L. Choi, J.R. Hattrick-Simpers, A.M. Joshi, I. Takeuchi, S.C. Barron, E. Campo, T. Chiang, S. Empedocles, J.M. Gregoire, A.G. Kusne, J. Martin, A. Mehta, K. Persson, Z. Trautt, J. Van Duren, A. Zakutayev, Appl. Phys. Rev. 4, 011105 (2017).

70. X.L. Wang, T.M. Holden, G.Q. Rennich, A.D. Stoica, P.K. Liaw, H. Choo, C.R. Hubbard, Physica B 385-386, 673 (2006)

71. S. Huang, Y. Gao, K. An, L. Zheng, W. Wu, Z. Teng, P.K. Liaw, Acta Mater. 83 137 (2015).

72. E.W. Huang, D. Yu, J.-W. Yeh, C. Lee, K. An, S.-Y. Tu, Scr. Mater. 101, 32 (2015) 73. K. An, Y. Chen, A.D. Stoica, MRS Bull. 44 (11), 878 (2019).

74. G. Kim, H. Diao, C. Lee, A.T. Samaei, T. Phan, M. Jong, K. An, D. Ma, P.K. Liaw, W. Chen, Acta Materialia (forthcoming), https://doi.org/10.1016/j.actamat.2019. 09.026 .

75. C. Cao, G. Yao, L. Jiang, M. Sokoluk, X. Wang, J. Ciston, A. Javadi, Z. Guan, I. De Rosa, W. Xie, E.J. Lavernia, J.M. Schoenung, X. Li. Sci. Adv. 5, eaaw2398 (2019). 76. S.A. Humphry-Baker, S. Garroni, F. Delogu, C.A. Schuh, Nat. Mater. 15, 1280 (2016). 77. L.-Y. Chen, J.-Q. Xu, H. Choi, M. Pozuelo, X. Ma, S. Bhowmick, J.-M. Yang, S. Mathaudhu, X.-C. Li, Nature 528, 539 (2015).

78. E.-W. Huang, H.-S. Chou, K.N. Tu, W.-S. Hung, T.-N. Lam, C.-W. Tsai C.-Y. Chiang, B.-H. Lin, A.-C. Yeh, S.-H. Chang, Y.-J. Chang, J.-J. Yang, X.-Y. Li, C.-S. Ku, K. An, Y.-W. Chang, Y.-L. Jao, Sci. Rep. 9, 14788 (2019).

79. P.H. Lin, H.S. Chou, J.C. Huang, W.S. Chuang, J.S.C. Jang, T.G. Nieh, MRS Bull. 44 (11), 860 (2019).

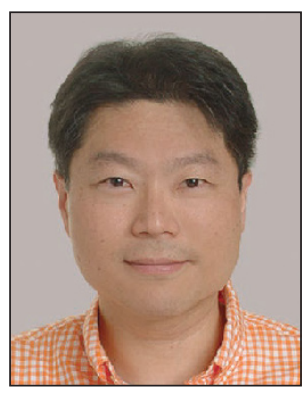

E-Wen Huang is an associate professor in the Department of Materials Science and Engineering at National Chiao Tung University, Taiwan. He obtained his PhD degree from The University of Tennessee in 2009. He is a recipient of the Ludo Frevel Crystallography Scholarship Award from the International Centre for Diffraction Data in 2009, Young Leaders Professional Development Award from TMS in 2016, and the Ta-You Wu Memorial Award in 2017. He is an editorial board member of Scientific Reports. Huang can be reached by email at ewhuang@g2.nctu.edu.tw. 


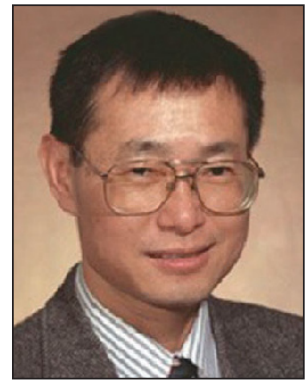

Peter K. Liaw is a professor and the Ivan Racheff Chair of Excellence at The University of Tennessee (UT). He is a Fellow of The Minerals, Metals \& Materials Society (TMS) and ASM International. His awards include UT's Outstanding Teacher Award, the Moses E. and Mayme Brooks Distinguished Professor Award, Engineering Research Fellow Award, National Alumni Association Distinguished Service Professor Award, the L.R. Hesler Award, the John Fisher Professorship at UT, and the TMS Distinguished Service Award. Liaw can be reached by email at pliaw@utk.edu.

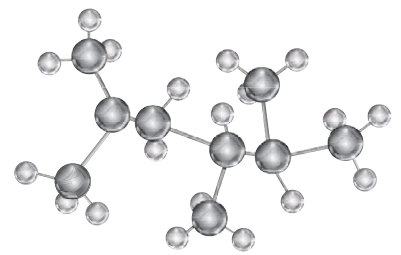

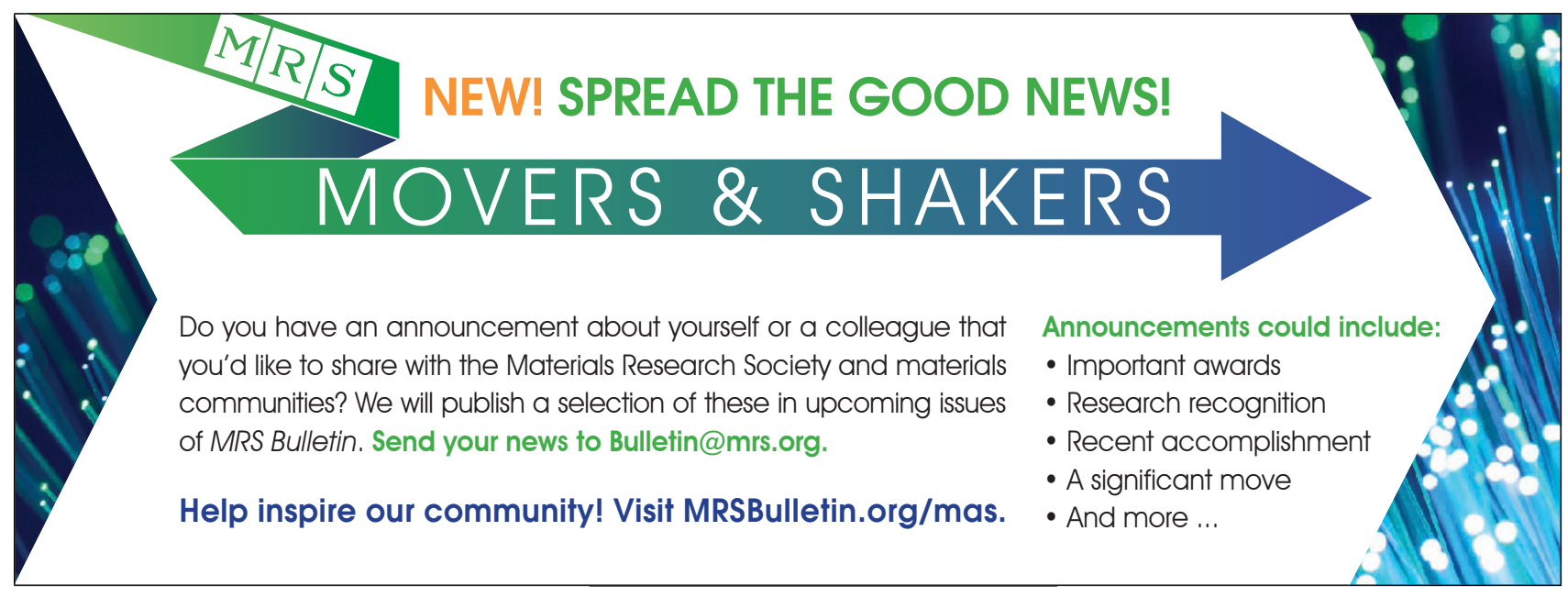

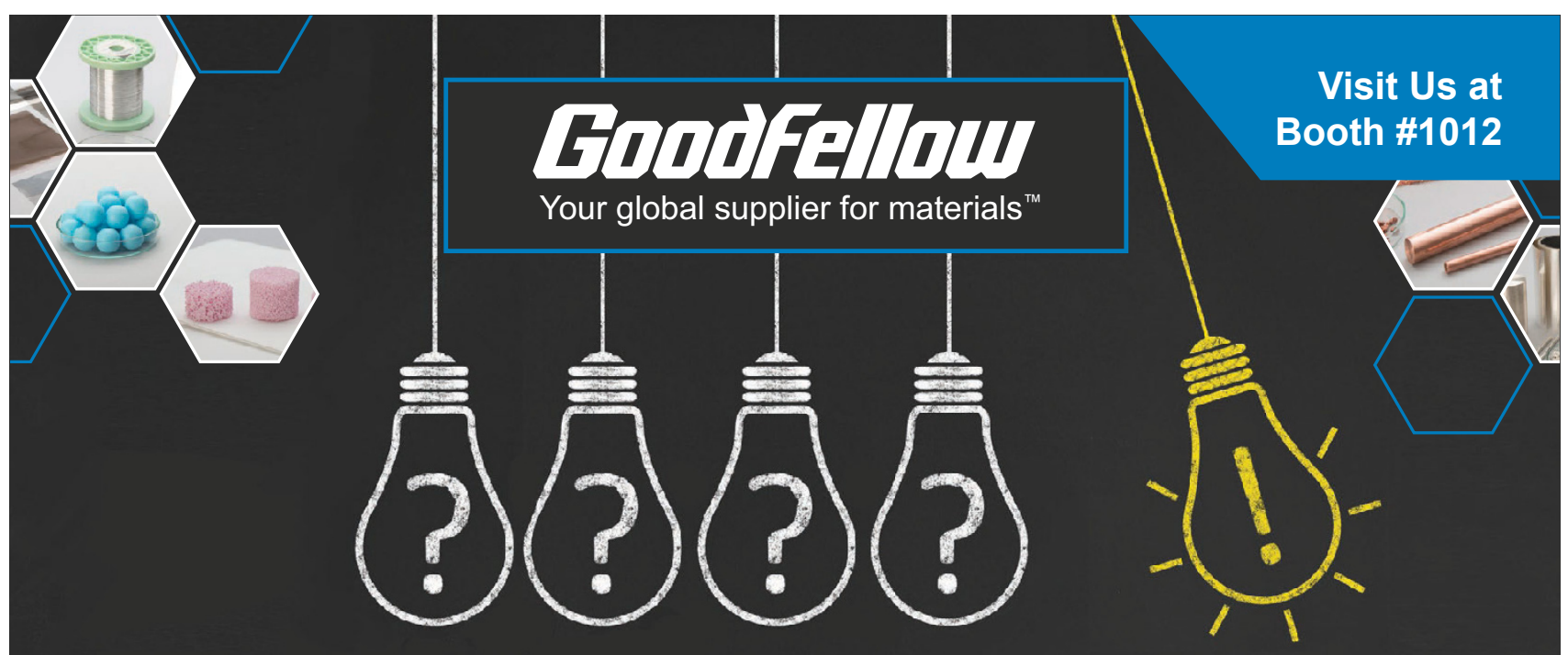

Have a materials question?

We have materials answers!

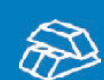

Metals
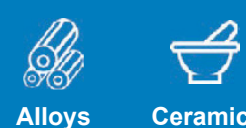

Ceramics

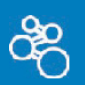

Polymers

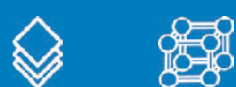

Composites Compounds www.goodfellowusa.com info@goodfellowusa.com 1-800-821-2870 